\title{
A General Equilibrium Analysis of Annuity Rates in the Presence of Aggregate Mortality Risk*
}

\author{
Justin van de Ven† and Martin Weale
}

National Insitute Discussion Paper No. 282

\begin{abstract}
This paper explores the pricing of annuities in a structural overlapping generations model in which the mortality rate of people when old is uncertain. A market clearing price for annuities is established below the fair price. At this price the willingness of old people to pay the young to carry old people's aggregate mortality risk is balanced by the willingness of the young to bear the risk. The model suggests that aggregate mortality risk is unlikely to be a major influence on annuity pricing.
\end{abstract}

Keywords: Annuity Rates; Tontines; Aggregate Mortality Risk; Risk Premium

JEL Classification: D1, G11, G12

${ }^{*}$ We should like to thank participants at the DEMWEL conference, Kittilä, March 2006, and especially Martin Flodén and Nico Keilman for valuable comments. The usual disclaimer applies.

$\dagger$ NIESR. jvandeven@niesr.ac.uk

‡NIESR. mweale@niesr.ac.uk 


\section{Introduction}

A life annuity provides an income stream for the duration of an individual's lifetime, thereby insuring them against the risk of unanticipated longevity. Annuities - whether provided by government implicitly through a public pension system, or purchased privately from an open market - consequently play an important role in financial planning for retirement throughout the developed world. Nevertheless, few studies have explored the workings of the annuities market, which is distinguished by its intertemporal nature and relation to demographic risk. This paper therefore uses an overlapping generations model to consider how the market clearing annuity price is affected by uncertainty regarding individual life-span.

Annuity rates offered on the UK market have fallen substantially over the last 25 years, from a high of $16 \%$ for 65 year old males in 1981, to $7 \%$ in 2006! This longterm trend has been attributed to two principal factors. First, mortality rates have also fallen considerably over the same period - a 65 year old male was estimated to have a life expectancy of 13.0 years in 1981, compared with 17.1 years now ${ }^{2}$ Secondly, the yield on long-term government debt has declined over the period, from $9.33 \%$ in 1986 to $3.84 \%$ in 2006.$^{3}$ Given existing interest and mortality rate profiles, Murthi et al. (1999), Finkelstein \& Poterba (2002), and Cannon \& Tonks (2003) report that the annuity rates provided by UK markets are approximately actuarially fair. Similar findings are also reported by Mitchell et al. (1999) for the US.

An evaluation of actuarial fairness provides an indication of the extent to which annuity markets provide value for money to consumers. It is important to note, however, that the evaluation of actuarial fairness is far from straight-forward. The analysis reported by Finkelstein \& Poterba (2002), for example, suggests that the nominal annuities of 65 year old males in the UK are approximately $10 \%$ below actuarially fair when based on the survival probabilities of the total population, but are very close to actuarially fair after adjusting individual mortality to reflect the size of the annuity actually purchased.4 This highlights the difficulties associated with identifying the appropriate

\footnotetext{
${ }^{1}$ The UK annuities market is one of the largest in the world, and therefore provides a useful reference point for discussion.

${ }^{2}$ See Government Actuary's Department website: http://www.gad.gov.uk

${ }^{3}$ Yields quoted for 20 year 0 coupon Gilts - see www.statistics.gov.au.

${ }^{4}$ This is because annuitants tend to live longer than the wider population, and because longevity also tends to increase with the size of the annuity purchased. In similar and slightly earlier work Murthi et al. (1999) suggest that roughly two thirds of the apparent difference between actual and fair annuity rates (based on aggregate mortality tables) can be accounted for by adverse selection.
} 
mortality rates to use for analysis. Furthermore, insurance companies may earn substantial profits despite paying premiums that are actuarially fair, if they earn a higher rate of return on capital than the yields on long-term debt which are commonly used to calculate an annuity's "moneys worth" (James \& Song (2001)). Indeed, if potential consumers of annuities consider a rate of return on capital that exceeds the yield on long-term debt, then the annuity yields offered by the market are likely to be less than actuarially fair, and this may go some way to explaining the "annuity puzzle" 5

A further issue is raised by the inherent uncertainty that characterises the market for annuities. Specifically, although uncertainty is associated with any forecast, in the United Kingdom there is a widespread view that the decline in mortality rates among the elderly over the last fifteen years has taken actuaries by surprise. As noted by the Pensions Commission in its Second Report, "in the early 1980s public pension policy and private pension provision decisions were based on the assumption that average male life expectancy at 65 in 2010 would be 15.1 years: the best estimate is now 20.1 years" (Pensions Commission (2005), p. 90). Obviously the mere fact that life is believed to have risen does not itself imply that forecasts of life expectancy are particularly uncertain, but the point is that most actuarial calculations involve forecasts of future mortality and, like all forecasts, these must be uncertain.

Given the uncertainty associated with mortality projections, it seems reasonable to suppose that a charge will be levied by providers of annuities in return for adopting cohort specific mortality risk. This paper focuses on the extent to which cohort specific risk is likely to depress annuity rates in a perfectly competitive market where both consumers and investors are characterised by risk averse preferences.

Very little analysis has been conducted to identify the effects of mortality risk on annuity rates. One exception is the study by Friedberg \& Webb (2005), which considers the use of longevity bonds as a method of hedging longevity risk. Longevity bonds are loan stocks that provide a yield which is proportional to the longevity of a cohort. Friedberg and Webb focus on a stock issued by the European Investment Bank that relates payments to the survival rate of the UK male cohort aged 65 in 2003. They assess the empirical magnitude of the risk associated with this loan, and use the Consump-

\footnotetext{
${ }^{5}$ Yaari (1965) showed that risk averse consumers will choose to annuitise all of their wealth when subject to an uncertain length of life, and actuarially fair annuity rates. Nevertheless, the private market for annuities tends to be thin in the absence of compulsion (e.g. Brown et al. (2001)). Brown (2001) considers the effects of choosing alternative interest rates for analysis, and Murthi et al. (1999) and Poterba (2001) consider possible explanations for the annuity puzzle.
} 
tion Capital Asset Pricing Model (Mehra \& Prescott 2003) to identify the associated risk premium. On the basis of this analysis, Friedberg \& Webb (2005) find that the longevity bond should trade at a discount of 2 basis points, which is less than the 20 basis point discount that was observed in the market. Friedberg and Webb suggest that the discount associated with the longevity bond was influenced by risk averse annuity providers purchasing bonds to hedge themselves against aggregate mortality risk.

It is not clear, however, that the CCAPM is a suitable tool for calculating the risk premium of longevity bonds. Specifically, the CCAPM is based upon the assumption of an infinitely lived consumer, which is at odds with the fact that the very reason for introducing a longevity bond is that people live for a finite period ${ }^{6}$ Since the investment decision becomes more complex when mortality constraints and periods of retirement are taken into consideration, it seems important to take these explicitly into account in pricing annuities in the context of mortality risk, which is the focus of the current paper.

Section 2 describes the overlapping generations model that we use to consider the effects of aggregate longevity uncertainty on annuity rates, and draws out some of the analytical results. Section 3 briefly describes numerical solution of the problem, and results of alternative simulations are presented in Section 4. Conclusions and directions for further research are summarised in Section 5 ,

\section{The Model}

We consider the question of how the annuity price is affected by mortality risk using a two period overlapping generations model. The first period of life is of unit length, while the length of the second period is uncertain. Each generation receives unit labour income in the first period of its life. It can choose to invest some of this income by selling annuities to the current old population 7 Annuities are transacted at the start of each period at a fixed price, and the repayment on them is proportional to the life-span of the old generation. Thus the annuity contracts sold by the young to the old are subject to aggregate mortality risk. Just as the young choose how much of their wealth to invest

\footnotetext{
${ }^{6}$ The influence of finite lives in the current context is partly mitigated by the role of individual bequests in intergenerational transmission of wealth, and by the fact that governments provide the majority of annuities in many countries around the world.

${ }^{7}$ The lifetime labour incomes of adjacent cohorts has an impact on the market clearing annuity price. In the current context we assume that each generation receives the same labour income. If, however, younger generations earned higher labour incomes than older generations, then the supply of annuities would, ceteris paribus, be higher, and the market clearing annuity rate more favourable to purchasers of annuities. The effect of this correlation remains an issue for further research.
} 
in annuities, so too the old decide to what extent they wish to annuitise the wealth that they hold at the start of their second period. A market-clearing price is established for annuities where the marginal willingness of the young to take on risk is balanced with the desire of the old to protect themselves from it. Given risk averse preferences, the market clearing annuity rate is consequently expected to be discounted, compared to the rate that would prevail in the absence of aggregate mortality risk.

On average the sellers of the annuities make a profit as compensation for the risk that they run in providing a guarantee to old people. While we consider only representative individuals from each generation, we assume that uninsured individuals are subject to the same mortality risk that is borne by sellers of annuities. Thus there is the assumption that uninsured individuals diversify their individual specific mortality risk as far as is possible within their cohort, for example by investing their wealth in a tontine 8 , an annuity where each cohort carries its own aggregate mortality risk. The results would be rather different if they did not have this option and that is a topic to be explored in future work.

We denote by $c_{y, i}$ consumption of generation $i$ when young, and $c_{o, i}$ consumption of generation $i$ when old. $w_{i}$ is the amount of wealth held by generation $i$ at the start of period 2. $t_{i}$ is the lifespan in the second period with $E\left(t_{i}\right)=t_{o}$ for all generations, $i$. $\pi_{i}$ is the rate at which generation $i$ can purchase an annuity when old. In exchange for an annuity purchase of $£ 1$, an annuitant receives a payment of $£ \pi_{i} / t_{o}$ per unit of time in retirement. $\phi_{i}$ is the proportion of wealth that old people in generation $i$ use to purchase annuities. $\phi_{i}^{\prime}$ is the proportion of old people's wealth in generation $i$, which young people in generation $i+1$ are prepared to annuitise. $\phi_{i}=\phi_{i}^{\prime}$ is therefore the equilibrium condition.

To simplify discussion, we assume that the interest rate is zero, and that the discount rate is unity. Thus the life-time utility of a representative individual from generation $i$ (hereafter referred to simply as generation $i$ ), measured from the start of their life, is

$$
U_{y, i}=U\left(c_{y, i}\right)+t_{i} U\left(c_{o, i} / t_{i}\right)
$$

The wealth of generation $i$ at the start of their old age is given by the amount that it saved from period $1,1-c_{y, i}$ plus the profit that it makes on the annuities it has sold to generation $i-1$

$$
w_{i}=\left(1-c_{y, i}+\phi_{i-1}^{\prime} w_{i-1}\left[1-\pi_{i-1} \frac{t_{i-1}}{t_{o}}\right]\right)
$$

\footnotetext{
${ }^{8}$ Named after Lorenzo Tonti who set up such a scheme for Louis XIV around 1653.
} 
The total amount it consumes when old depends on the proportion of wealth that it annuitises, given by $\phi_{i}$ and its lifespan, $t_{i}$.

$$
\begin{aligned}
c_{o, i} & =\phi_{i} w_{i} \frac{\pi_{i} t_{i}}{t_{0}}+\left(1-\phi_{i}\right) w_{2} \\
& =\left(1-c_{y, i}+\phi_{i-1}^{\prime} w_{i-1}\left[1-\pi_{i-1} \frac{t_{i-1}}{t_{o}}\right]\right)\left(\frac{\pi_{i} t_{i}}{t_{0}} \phi_{i}+1-\phi_{i}\right)
\end{aligned}
$$

Thus life-time utility is

$$
U_{y, i}=U\left(c_{y, i}\right)+t_{i} U\left\{\left(1-c_{y, i}+\phi_{i-1}^{\prime} w_{i-1}\left[1-\pi_{i-1} \frac{t_{i-1}}{t_{o}}\right]\right)\left(\frac{\pi_{i} \phi_{i}}{t_{0}}+\frac{\left(1-\phi_{i}\right)}{t_{i}}\right)\right\}
$$

Young people in generation $i$ are considered to optimise by choosing their consumption, $c_{y, i}$, and how much of their non-consumed wealth to invest in annuities, $\phi_{i-1}^{\prime}$. Old people in generation $i-1$, by contrast select how much of their wealth to spend on annuities, $\phi_{i-1}$, to maximise expected utility in their second period

$$
U_{o, i-1}=t_{i-1} U\left\{w_{i-1}\left(\frac{\pi_{i-1}}{t_{0}} \phi_{i-1}+\frac{1-\phi_{i-1}}{t_{i-1}}\right)\right\}
$$

We assume that $\operatorname{Var}\left(t_{i}\right)=\sigma^{2}$ for all $i$, and also that the life-spans of successive generations are independent of each other, leaving for future study the case where they are correlated.

Equation (5) indicates that the demand for annuities by generation $i$ when old depends upon their wealth, $w_{i}$, which in turn depends upon the longevity of the immediately preceding generation $i-1$ (equation 2). Hence, the market clearing annuity price paid by generation $i, \pi_{i}$, is uncertain when the generation is young. Although no analytical solution exists to the inter-temporal utility maximisation problem for the young generation, the problem can be solved numerically by backward induction. It is useful, however, to simplify the problem here by assuming that $\pi_{i}=\pi$ for all $i$, which enables convenient expressions to be derived for the expected utility of young and old generations. This simplification - which is returned to in the conclusion - is likely to be of second order importance with regard to the implied relationship between longevity uncertainty and annuity rates, and helps to clarify the current discussion. A rigorous consideration of the inter-temporal utility maximisation problem described above remains an issue for further research.

We solve the problem numerically, using second order Taylor expansions to calculate expected utility in the light of uncertainty about $t_{i}$ and $t_{i-1}$. Looking first at the expected 
value of $U_{o, i-1}$

$$
\begin{aligned}
E\left(U_{o, i-1}\right) & =t_{o} U\left\{\frac{w_{i-1}}{t_{0}}\left(\pi \phi_{i-1}+1-\phi_{i-1}\right)\right\}+\left.\frac{\sigma^{2}}{2} \frac{\partial^{2}}{\partial t_{i-1}} t_{i-1} U\left\{w_{i-1}\left(\frac{\pi}{t_{0}} \phi_{i-1}+\frac{1-\phi_{i-1}}{t_{i-1}}\right)\right\}\right|_{t_{o}} \\
& =t_{o} U\left\{\frac{w_{i-1}}{t_{0}}\left(\pi \phi_{i-1}+1-\phi_{i-1}\right)\right\}+\frac{\sigma^{2}\left(1-\phi_{i-1}\right)^{2} w_{i-1}^{2}}{2 t_{o}^{3}} U^{\prime \prime}\left\{\frac{w_{i-1}}{t_{0}}\left(\pi \phi_{i-1}+1-\phi_{i-1}\right)\right\}
\end{aligned}
$$

In the standard way, the expected utility of old people is influenced by the variance of their life-span, with the impact depending only on the extent to which they are not annuitised.

For young people at the start of period 1 there are two sources of uncertainty. To the extent that they sell annuities, they are affected by the uncertainty about the mortality of the old people to whom the annuities are sold. And they are also affected by uncertainty about their own life duration, to the extent that they are not insured. These two terms are shown in the second and third lines of the following expression

$$
\begin{aligned}
E\left(U_{y, i}\right)= & U\left(c_{y, i}\right)+t_{0} U\left\{\left(1-c_{y, i}+\phi_{i-1}^{\prime} w_{i-1}[1-\pi]\right)\left(\frac{\pi \phi_{i}+1-\phi_{i}}{t_{0}}\right)\right\} \\
& +\frac{\sigma^{2}}{2}\left(\frac{\pi w_{i-1} \phi_{i-1}^{\prime}}{t_{0}^{2}}\right)^{2}\left(\pi \phi_{i}+1-\phi_{i}\right)^{2} t_{0} U^{\prime \prime}\left\{\left(1-c_{y, i}+\phi_{i-1}^{\prime} w_{i-1}[1-\pi]\right)\left(\frac{\pi \phi_{i}+1-\phi_{i}}{t_{0}}\right)\right. \\
& +\frac{\sigma^{2}}{2} \frac{\left(1-\phi_{i}\right)^{2}\left(1-c_{y, i}+\phi_{i-1}^{\prime} w_{i-1}[1-\pi]\right)^{2}}{t_{0}^{3}} U^{\prime \prime}\left\{( 1 - c _ { y , i } + \phi _ { i - 1 } ^ { \prime } w _ { i - 1 } [ 1 - \pi ] ) \left(\frac{\pi \phi_{i}+1}{t_{0}}\right.\right.
\end{aligned}
$$

We work with a constant elasticity of substitution utility function, $U(x)=\Gamma+\frac{x^{1-\gamma}}{1-\gamma}$ and $U^{\prime \prime}(x)=-\gamma x^{-1-\gamma}$ with $\gamma \neq 1$. $\Gamma$ is selected to ensure that, for any value of $\gamma$, second period utility is increasing in lifespan. Hence, the model excludes suicide as a solution to longevity.

The structure of the model can be seen clearly in figure 1, which shows, for $\gamma=3$, $t_{i}=t_{i-1}=t_{0}=0.6$ and $\sigma^{2}=0.01,0.04$, the positions of the demand and supply curves for annuities .9 Figure 1 indicates that demand falls and supply rises as the annuity rate falls below the actuarially fair rate. When uncertainty is set such that $\sigma^{2}=0.01$, it can be seen that the demand for annuities by old people falls off fairly steeply as the annuity rate declines. The willingness of young people to supply annuities rises almost as steeply, and the equilibrium price is given by the intersection of the supply curve with demand. With higher uncertainty, both the demand and supply curves flatten out,

\footnotetext{
${ }^{9}$ The assumption that $t_{i}=t_{i-1}=t_{0}$ implies that, although individuals take into consideration the uncertainty of life-spans, the out-turns are equivalent to ex ante point estimates.
} 
resulting in a substantially lower market clearing annuity rate. Higher risk aversion has a similar effect on the market clearing annuity prices as higher risk for a given value of $\gamma$ - as aversion to risk rises the impact of the risk discount on willingness both to provide and to buy annuities declines.

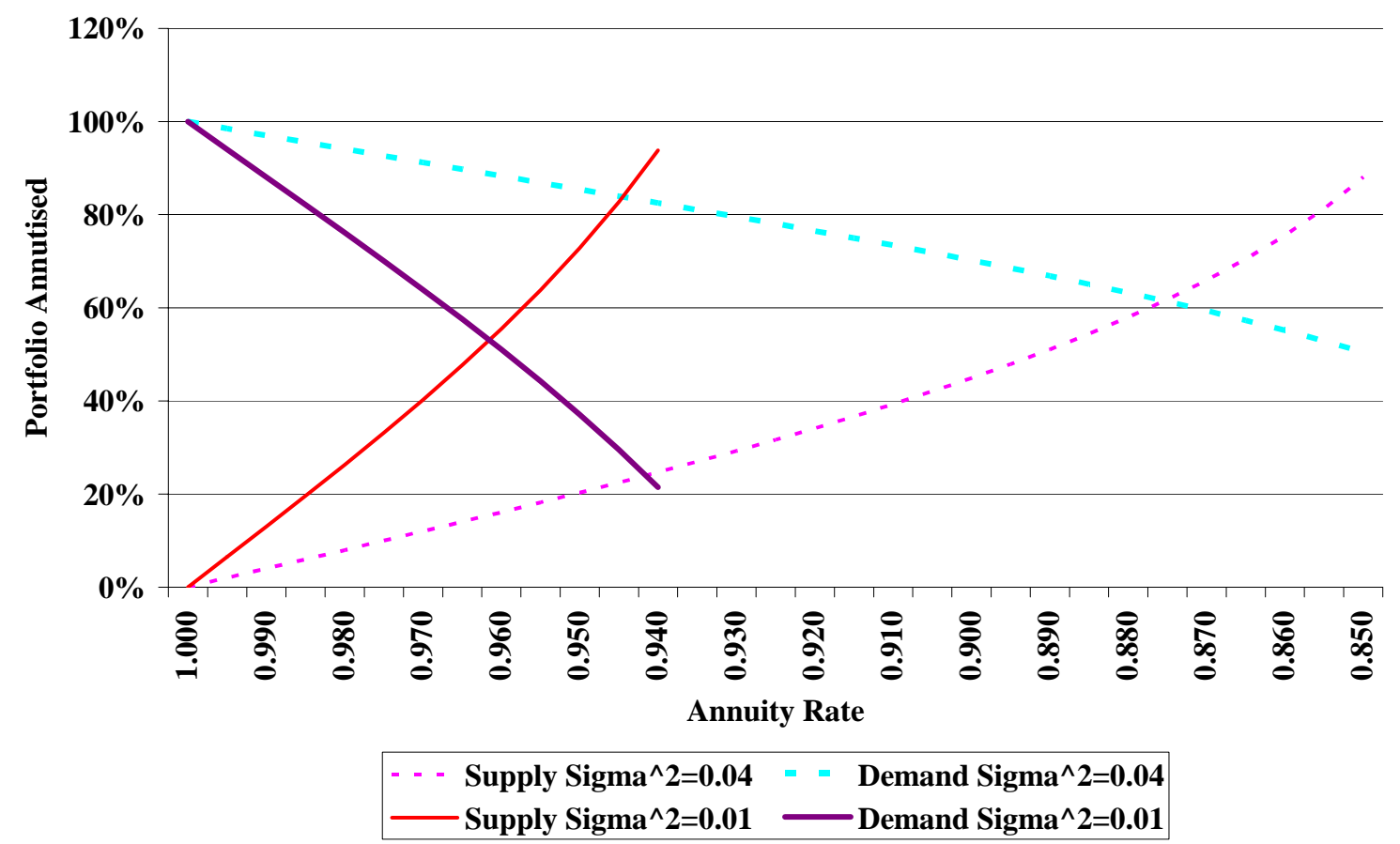

Figure 1: Supply and Demand for Annuities.

With higher risk aversion and also with greater uncertainty the two curves flatten out, so that the equilibrium price is reduced.

\section{Model Solution}

The model does not have an analytical solution and we therefore solve numerically for the three choice variables described by the utility maximisation problem (the amount that the individuals choose to consume when young, the proportion of old people's wealth that the young are prepared to annuitise, and the proportion of wealth which old people would like to annuitise), for an arbitrarily chosen annuity rate. The annuity rate is then adjusted to clear the annuity market. The model is programmed in MATLAB and makes use of the optimising routines available there.

The assumption of a constant elasticity of substitution utility function means that, given values for the parameters of the model, the proportion of wealth that old people 


\begin{tabular}{|c|c|c|c|c|}
\hline & $\gamma$ & $\pi$ & $\mathrm{c}$ & $\phi$ \\
\hline$\sigma^{2}=0.01$ & 6.0 & 0.933 & 0.618 & 0.572 \\
& 5.0 & 0.942 & 0.619 & 0.557 \\
& 4.0 & 0.951 & 0.620 & 0.543 \\
& 3.0 & 0.962 & 0.622 & 0.530 \\
& 2.0 & 0.973 & 0.623 & 0.519 \\
& 1.0 & 0.986 & 0.625 & 0.509 \\
& 0.5 & 0.993 & 0.626 & 0.504 \\
& 0.1 & 0.999 & 0.626 & 0.501 \\
\hline$\sigma^{2}=0.04$ & 6.0 & 0.833 & 0.602 & 0.732 \\
& 5.0 & 0.840 & 0.606 & 0.693 \\
& 4.0 & 0.853 & 0.609 & 0.653 \\
& 3.0 & 0.875 & 0.614 & 0.613 \\
& 2.0 & 0.906 & 0.619 & 0.573 \\
& 1.0 & 0.948 & 0.625 & 0.534 \\
& 0.5 & 0.973 & 0.628 & 0.516 \\
& 0.1 & 0.994 & 0.631 & 0.503 \\
\hline
\end{tabular}

Table 1: Effects of Aggregate Mortality Risk on the Annuity Market

would like to annuitise depends only on the annuity rate and is independent of the actual amount of wealth that they hold. For a starting price, we find the proportion of wealth that old people would like to annuitise $\left(\phi_{i}\right)$. With an exogenous value for the actual wealth holding of old people, $w_{i}$, we then find the optimal values of the three decision variables of young people $\left(c_{y, i+1}, \phi_{i}^{\prime}, \phi_{i+1}\right)$. We then calculate the new value of old age wealth implied by these and also reduce $\pi$ by an amount proportional to $\phi_{i}^{\prime}-\phi_{i}$. The process continues until $\phi_{i}^{\prime}, \phi_{i}$ and $\phi_{i+1}$ converge. It should be noted that, although $w_{i}$ is influenced by the optimisation choices, it is exogenous to the optimisation decision of the young. This reflects the fact that the wealth of generation $i$ in old age is not a choice variable of generation $i+1$.

\section{Results}

The only structural assumption of the model is that $t=0.6$. We present results for two values of $\sigma^{2}, 0.04$ and 0.01 , corresponding to standard deviations of $t$ of 0.2 and 0.1 respectively. We also look at a range of values of $\gamma$ including $\gamma=1.01$ so as to avoid having to respecify the model for the situation where $\gamma=1$.

The results reported in table 1 are coherent with intuition in so far as it can be formed about a market-clearing process. The annuity rate, $\pi$, is decreasing in $\gamma$, the coefficient 
of relative risk aversion, and annuity rates are low when there is high uncertainty about future life-spans $\left(\sigma^{2}=0.04\right)$. For very low levels of risk aversion the annuity rate rises towards 1 (actuarially fair rate) as would be expected.

The amount of first-period consumption is also decreasing in the degree of risk aversion. This does not represent an income effect, because the expected effect of annuity transactions on life-time income is zero; if annuity rates are low someone expects to make a good profit on the annuities which they sell when young, but at the same time, does not do very well on the annuities that they buy when old. Since the model is solved in a steady state these two effects must cancel each other out. Rather it reflects the fact that, with high levels of risk aversion, young people are more concerned about the uncertainty in their consumption when old; thus they undertake precautionary saving at high levels of risk aversion. The extent of annuitisation, given by $\phi$, increases with risk aversion, and with the extent of uncertainty in mortality rates. This suggests that demand reacts more strongly to these factors than does supply.

The results may be contrasted with what would emerge if the sale of an annuity were a simple bet by a risk-averse individual - in other words what might happen if we settled for a partial solution and were not concerned about finding the market clearing annuity rate. We would then use the standard formula for pricing a bet by an individual with relative risk aversion $\gamma$; the rate would be given as $\pi=1-\gamma \sigma^{2} / 2$. It is straightforward to see that this gives annuity rates that are higher than those shown in table 1; the consumption risk faced by the young when selling annuities is greater than that implied by the simple model and so the price is driven up considerably.

\section{Conclusions}

A general equilibrium framework is needed to assess the risk discount which is likely to be applied to annuity rates to reflect the fact that sellers of annuities cannot protect themselves from aggregate mortality risk. We have studied a framework in which annuities are supplied by young people to old people and the risk discount is established at a level which clears the market. Our analysis, set out in the context of representative members of young and old cohorts, assumes that old people have the choice between buying an annuity which protects them completely from mortality risk and investing in a tontine which protects them from most mortality risk but which leaves them exposed to the aggregate mortality risk faced by the cohort to which they belong. Subject to 
these conditions, we find that moderate rates of aggregate mortality risk are likely to imply that market clearing annuity rates are between $1 \%$ and $7 \%$ below actuarially fair rates, depending upon the extent of risk aversion.

The model set out here is obviously stylised. It does, however, focus on the fact that annuities must be supplied by someone, and that the suppliers have to be people of working age. Thus the terms on which they supply annuities are crucial. While it is possible that some of the aggregate mortality risk described here could be smoothed by intergenerational transfers - either through government finances or private bequests - it is unlikely that these channels will fully insure any one generation. And in the absence of contracts with unborne generations, people of working age have no guarantee that they will have access to an annuity market when they reach retirement. Furthermore, it is unlikely that alternative investment media would have a major impact on the results unless the returns on such media are closely correlated with mortality shocks. These issues suggest that aggregate mortality risk may have an important influence on market clearing annuity rates, as described here.

An number of issues would seem to warrant further research. One is the assumption that there is no individual specific risk. In the absence of tontines, the demand for annuities by old people in the current context would be raised appreciably and the risk discount on the annuity rate would also be increased as young people demand greater reward for the extra risk that they carry. Furthermore, the analysis reported here is time inconsistent, in the sense that it abstracts from temporal variation in the market clearing annuity rate that is implied by aggregate mortality risk.

To understand the potential implications of this second restriction, it is useful to consider a specific example. If the current old generation lives unexpectedly long, then the current young generation has unexpectedly little wealth when it reaches old age. This means that, even though its desired purchase of annuities as a proportion of second period wealth maintains its standard relationship to the annuity rate, nevertheless, the total amount that it wishes to spend on annuities will be low. In consequence, even if the mortality risks are serially uncorrelated, the market clearing annuity rate at which young people will purchase annuities is likely to be slightly higher than it would be if the current old people had died as expected. Thus the realisation is likely to be more favourable to the current young than might seem the case if one focused on the effects of mortality shocks alone. The annuity rate which the current young will face when old is negatively correlated with the life-span of the current old and this negative correlation 
will increase the willingness of the current young to sell annuities as compared to the results of section 4. Such an effect can be seen as an example of Le Chatelier's principle

- that nature tends to reverse a change. However, it also points to a mechanism whereby the cost of meeting unexpected variations in life-span is spread, at least to some extent, beyond the cohort which experiences the shock and the younger cohort which has sold them annuities.

Incorporation of this effect can be obtained by numerical solution of the intertemporal Bellman equation via backward induction. It will then be possible to explore how far the annuity market offers a means for spreading these demographic shocks across future generations. In the mean time the results in figure 1 can be seen as setting lower limits to annuity rates in the face of mortality risk.

\section{References}

Brown, J. R. (2001), 'Private pensions, mortality risk, and the decision to annuitize', Journal of Public Economics 82, 29-62.

Brown, J. R., Mitchell, O. S., Poterba, J. M. \& Warshawsky, M. J. (2001), The Role of Annuity Markets in Financing Retirement, MIT Press, Cambridge, MA.

Cannon, E. \& Tonks, I. (2003), UK annuity rates and pension replacement ratios 19572002. UBS Pensions Research Program Discussion Paper 8.

Finkelstein, A. \& Poterba, J. (2002), 'Selection Effects in the Market for Individual Annuities: New Evidence from the United Kingdom', Economic Journal 112, 2850.

Friedberg, L. \& Webb, A. (2005), Life is Cheap: Using Mortality Bonds to Hedge Aggregate Mortality Risk. Centre for Retirement Research Working Paper No 2005-13.

James, E. \& Song, X. (2001), Annuity markets around the world: money's worth and risk intermediation. CeRP Working Paper 16/01.

Mehra, R. \& Prescott, E. (2003), The Equity Premium in Restrospect, in G. Constantinides, M. Harris \& R. Stulz, eds, 'Handbook of the Economics of Finance', JAI Press. 
Mitchell, O. S., Poterba, J. M., Warshawsky, M. J. \& Brown, J. R. (1999), 'New evidence on the money's worth of individual annuities', American Economic Review 89, 1299-1318.

Murthi, M., Orszag, J. M. \& Orszag, P. R. (1999), The value for money of annuities in the UK: theory, experience and policy. Birkbeck College Discussion Paper.

Pensions Commission (2005), A New Pensions Settlement for the Twenty-First Century, TSO, Norwich.

Poterba, J. M. (2001), 'Annuity Markets and Retirement Security', Fiscal Studies 22, 249-279.

Yaari, M. (1965), 'Uncertain Life-time, Life Insurance and the Theory of the Consumer', Review of Economic Studies 32, 137-150. 